\title{
The role of Emotional response and Information processing at the Achievement level of Epee fencers
}

\section{Dr. Mona Mohamed-Kamal Hijazi}

This research aimed to identify the role of the emotional response and information processing in the achievement level of Epee fencers, under 20, registered in the Egyptian Federation of Fencing. The researcher employed a descriptive method by using survey method in a sample of (35) Epee fencers registered in the 2019/2020 season of the Egyptian Federation of Fencing. (7) for survey, (28) for basic study. The basic sample was comprised of (18) males and (10) females who participated in the 20-year stage of Egypt Cup 1 Championship, the researcher used Emotional response scale, Prepared by Thomas A. Tutko, the Arabic version prepared by (Allawi, Shimon, It measures seven separate Traits (Desire Assertiveness - Sensitivity - Tension Control - Confidence - Personal Accountability - SelfDiscipline), consists of (42) phrases, with a five-point grading scale, and Information Processing (INFP), was designed by Nideffer and translated to Arabic by Allawi (1998). which includes 19 phrases, The total score of the test ranges between (19 - 95) points. the most important results was that there is a positive correlation between Information Processing and both (Tension Control, Confidence, Self-Discipline), there is a positive correlation between classification and (Sensitivity, Tension Control, Confidence, Self-Discipline, and Information Processing), and the availability of a good level of the emotional response traits (Tension Control, Confidence, Self-Discipline), and information processing is an important and effective factor in fencer's achievement level.

Key words: emotional response, information processing, fencing.

\section{Introduction:}

Psychological, physical and educational features play an important role in determining the player's success in performing on the field, there are two types of personality features that affect athletic performance, they are cognitive, emotional, and Sentimental features. Emotional sentimental features are associated with distinctive performance, which is meant by what an individual performs and how he performs it. It reveals an individual's motivations, inclinations, and psychological factors behind performance, in a particular style or method (Abdel-Fattah, A. A., El-Ruby, A. O., 1986, 65).

Emotions are a group of Interlaced and interrelated psychological processes, in which the emotional, cognitive, motivational, and psychological components are important and necessary. "Emotions play a fundamental role with different motivations and needs, and the extent of their relationship to the multiple activities practiced by the individual", in addition to its negative and positive effects in the physical, mental and social aspect of the individual personality.

The emotional response is a set of psychological features that have an impact on the level of players performance and achievement. the emotional response of the player determines his ability to face the competition, which can be obtained through the emotional features that characterize the emotional behavior of the athlete, and represent the general behavior of personal effectiveness, And covers a variety of Qualitative responses that the athlete appears during the competition, such as emotional poise, self-control, positive ambition, and self-confidence (Annan, M. A., 1995, 100). The emotional response has seven separate psychological characteristics that express different orientations and have an impact 
in the field of sports, namely (Desire, Assertiveness, Sensitivity, Tension Control, Confidence, Personal Account Ability, and Self-Discipline).

Although some scholars have suggested that an emotional response does not always require cognitive processing, for others, the cognitive system is a basic rule, Because the individual does not respond emotionally to stimuli (Catalysts) that are believed to have no meaning or significance (Marc V. Jones, 2003, 472). Hence, the emotional and cognitive systems exchange the effect, as the emotional charge of some information affects the functioning of the cognitive system, the latter regulates emotional responses in different interactive contexts. Many studies have shown that emotion affects the functioning of various cognitive processes such as perception, attention and memory. (Melhem, S. M., (2002), 211212) also indicates that a person's level of mental abilities, his cognitive structure and the effectiveness of his information-processing system affect the pattern, capacity, and effectiveness of his attention. Therefore, we find that the more intelligent individuals, the greater their sensitivity in receiving stimuli, and their attention more accurate, because of their high level of mental alertness.

Whereas, mental processes such as attention, perception, intelligence, expectation, reaction, and emotional factors are among the most important topics that should be taken care of, due to the great role they play in motor performance in fencing, and also in the emotions and responses of the player, As the use of mental abilities and emotional factors to the maximum extent, increases the effort made by the player, whether in training or competitions (Hijazi, 2013, 196). James 1890 had previously assumed that emotion strengthened remembering. However, this does not hide the fact that the study of the effect of emotion on cognitive functions is neglected. Even cognitive psychology at its beginnings neglected to examine the effect of emotions on cognitive processes, given its reliance on the computer unemotional model in the study of mind (LeDoux, 1996). This has been rectified and the interest in studying emotion and the interaction between the cognitive and emotional systems in processing information has increased, and it turns out that the emotionality of stimuli affects the processing of information.

Emotions are not only the result of processing information in the brain, but also directly affect the processes of perception, attention, learning, memory, thinking and problem solving in the brain (Tyng CM, et al., 2017). (Tendler, A., Wagner, S., 2015) also finds that different emotions make the brain work differently, including cognitive processes such as learning and memory.

Most of the time of fencing, performance is fast with less time to think, (Di Russo, Taddei, Apnile, \& Spinelli, 2006) indicate that even world class fencers have no more than average reaction time, and in the most important duels, among competitors of similar levels, who reach the final touches or the last seconds, the superior performance is not only due to the physiological components, but also, above all, the better ability to anticipate the target areas targeted by the opponent, by monitoring his preparatory stage. Here, mental performance is always the decisive factor, and this depends on the speed of information processing

According to information processing theory, our sensory receptors receive a lot of information from the external environment, and store it in the sensory record for a short time, but little of this information gets attention and concern, then it moves to the next stage, and the processing is done (Smith, P., Ragan, T., 2004, 146). And the processing of information sent through the senses goes through three stages: cognition, interpretation, and mental processing based on representation, in which the information is processed from the time it is 
received perceptively to the time it enters the cognitive system. The correct response in the perceptive situation depends on many factors, including perceptive attitude characteristics and the excess burden of inputs it may contain, the subjective characteristics of individuals, their motives, and their needs.

Fencing is a fast-moving sport, in which players are exposed to enormous time pressures; As in racket sports, the interval for preparing their motor responses is so short that they have to anticipate the intentions of the opponent, Haase \& Mayer (1978), (Azémar, 1999). And because the speed of perception of senses to obtain information affects the effectiveness of technical and tactical movements in fencing, So the early anticipate of the target areas targeted by the opponent attack is a decisive factor in performance level (Roi $\&$ Bianchedi, 2008). This explains the importance of the speed with which information is processed for fencers. The researcher believes that this relationship between information processing and the achievement level of fencers is affected by the nature of the emotional response of the players, so the researcher saw the need to study the role of the emotional response and information processing in the achievement level of Epee fencers.

\section{Aim of the research:}

This research aimed to identify the role of the emotional response and information processing in the achievement level of Epee fencers, 20-year stage, registered in the Egyptian Federation of Fencing.

\section{Hypotheses of the research:}

- There is a statistically significant correlation between fencer's achievement level, emotional response, and information processing.

- There are statistically significant differences between the upper and lower groups (achievement level) in both the emotional response and information processing.

\section{Materials and Methods}

\section{Data collection}

\section{Emotional response scale}

Prepared by Thomas A. Tutko, the Arabic version was prepared by (Allawi, Shimon), It measures seven separate Traits (Desire - Assertiveness - Sensitivity Tension Control - Confidence - Personal Accountability - Self-Discipline), consists of (42) phrases, with a five-point grading scale, the phrases in the direction of the Trait are given the following points, always $=5$ points, often $=4$ points, sometimes $=3$ points, rarely $=$ two points, never $=$ one point. While the statements are given the opposite direction of the Trait, always $=1$ point, often $=2$ points, sometimes $=3$ points, rarely $=4$ points, never $=5$ points. The scale does not have a total score, the scores of each trait are collected separately (Allawi, M., 1998, 34-42).

\section{Information Processing Test}

Test of Attentional and Interpersonal Style (TAIS) was designed by Nideffer and translated by Allawi (1998). The test consisted of seven dimensions, including Information Processing (INFP), which includes 19 phrases, The total score of the test ranges between (19 - 95) points (Allawi, M., 1998, 508-514).

\section{research method}

Considering the nature of the research, the researcher used the descriptive method, which is not only limited to data collection and classification but also, includes an interpretation of these data. (Abdel-Hamid, J., KazemA.K., 2002: 134).

\section{Participants}


The research sample included (35) fencers registered in the 2019/2020 season of the Egyptian Federation of Fencing. (7) for survey, (28) for basic study. The basic sample was comprised of (18) males and (10) females, selected by Multistage random method, (Bahy, M.H,. Al-Azhary, M.A., 2015) represent (Nasr City, El-Maadi, and El Moassasa) clubs, who participated in the 20-year stage of Egypt Cup 1 Championship. They were divided according the Achievement level (classification) into three groups, (Upper group, middle group, lower group), the number of both the upper and the lower groups were (10) fencers, while the middle group was (8) fencers.

\section{Procedures}

\section{Survey study}

The researcher conducted a survey in a sample of (7) fencers from the same community, but who were not included in the study population on September $1 \cdot, 2019$.

\section{Scientific coefficients for tests:}

\section{First: validity}

For Emotional response scale, the researcher calculated the construct validity through internal consistency by finding the correlation coefficients between each phrase and the total sum of the trait, which ranged between .757 and .956 (statistically significant at $95 \%$ confidence level). This means that the scale has an acceptable degree of concept or composition validity (internal consistency).

For Information Processing Test, the validity coefficient ranged from 0.756 to 0.934 , and the Alpha reliability coefficient was 0.912 .

\section{Second: reliability}

For Emotional response scale, the researcher calculates the test reliability by Cronbach's alpha coefficient equation, the value of alpha coefficient was ranged between 0.825 and 0.983 . which means that the scale has an acceptable degree of reliability.

For Information Processing Test, The Scale reliability was calculated by using Alpha Cronbach equation, the value of alpha coefficient was 0.912. Were statistically significant at $95 \%$ confidence level.

\section{Basic study:}

The researcher conducted the Emotional response scale and Information Processing Test in the basic study sample on September 15 - 20, 2019.

\section{RESULTS}

Table (1)

Descriptive statistics for study sample in Emotional response traits, Information Processing and achievement level $n=35$

\begin{tabular}{ccccc}
\hline Variables & Mean & Median & Std. Deviation & Skewness \\
& & & & \\
\hline Desire & 16.429 & 16.000 & 3.108 & 0.364 \\
\hline Assertiveness & 18.000 & 18.500 & 3.115 & -0.554 \\
\hline Sensitivity & 17.286 & 17.000 & 2.462 & 0.126 \\
\hline Tension Control & 16.179 & 16.000 & 2.816 & -0.046 \\
\hline Confidence & 17.821 & 17.000 & 2.597 & 0.348 \\
\hline Personal Accountability & 16.214 & 16.500 & 2.658 & 0.083 \\
\hline
\end{tabular}




\begin{tabular}{ccccc}
\hline Self-Discipline & 19.214 & 20.000 & 2.500 & -0.446 \\
\hline Information Processing & 54.964 & 55.500 & 6.046 & -0.860 \\
\hline Achievement level & 24.143 & 19.500 & 18.836 & 1.064 \\
\hline
\end{tabular}

Table (') showed that the basic research sample obtained an intermediate level for all emotional response traits, as well as an intermediate level for processing information.

Table (2)

The correlation matrix between Emotional response traits, Information Processing and Achievement level $\mathbf{n}=\mathbf{2 8}$

\begin{tabular}{|c|c|c|c|c|c|c|c|c|c|c|c|}
\hline Variables & Mean & $\begin{array}{c}\text { Std. } \\
\text { Deviatio } \\
n\end{array}$ & $\begin{array}{c}\text { Desir } \\
\text { e }\end{array}$ & $\begin{array}{c}\text { Assertiven } \\
\text { ess }\end{array}$ & $\begin{array}{c}\text { Sensitivit } \\
y\end{array}$ & $\begin{array}{c}\text { Tensio } \\
\mathbf{n} \\
\text { Contro } \\
\text { I }\end{array}$ & $\begin{array}{l}\text { Confiden } \\
\text { ce }\end{array}$ & $\begin{array}{c}\text { Persona } \\
\text { I } \\
\text { Account } \\
\text { ability }\end{array}$ & $\begin{array}{c}\text { Self- } \\
\text { Discipline }\end{array}$ & $\begin{array}{c}\text { Information } \\
\text { Processing }\end{array}$ & $\begin{array}{c}\text { Achievemen } \\
\text { t level }\end{array}$ \\
\hline Desire & 16.429 & 3.108 & & 0.134 & 0.221 & -0.254 & -0.022 & 0.136 & -0.232 & -0.121 & -0.022 \\
\hline Assertiveness & 18.000 & 3.115 & & & 0.227 & 0.160 & 0.046 & -0.224 & 0.100 & 0.035 & -0.148 \\
\hline Sensitivity & 17.286 & 2.462 & & & & 0.153 & 0.315 & 0.256 & 0.134 & 0.210 & $-0.379 *$ \\
\hline Tension Control & 16.179 & 2.816 & & & & & $0.486^{*}$ & 0.292 & $0.489 *$ & $0.544^{*}$ & $-0.554 *$ \\
\hline Confidence & 17.821 & 2.597 & & & & & & 0.188 & $0.514^{*}$ & $0.575^{*}$ & $-0.682 *$ \\
\hline $\begin{array}{c}\text { Personal } \\
\text { Accountability }\end{array}$ & 16.214 & 2.658 & & & & & & & -0.102 & 0.249 & -0.273 \\
\hline Self-Discipline & 19.214 & 2.500 & & & & & & & & $0.552^{*}$ & $-0.649 *$ \\
\hline Information Processing & 54.964 & 6.046 & & & & & & & & & $-0.797^{*}$ \\
\hline Achievement level & 24.143 & 18.836 & & & & & & & & & \\
\hline
\end{tabular}

$r$ Table value for $d f{ }^{\top \vee}$ and the level of $0.05=0.374 ; *(p<0.05) ; * *(p<0.01)$.

Table (2) showed a statistically significant correlation between information processing and each of (Tension Control, Confidence, Self-Discipline), There are also a statistically significant correlation between Achievement level, and each of (Sensitivity, Tension Control, Confidence, SelfDiscipline, and Information Processing).

Table ( ${ }^{\sim}$ ) Significant differences between the upper and lower groups (Achievement level) in Emotional response traits and Information Processing

\begin{tabular}{|c|c|c|c|c|c|c|}
\hline Variables & groups & $\mathbf{N}$ & Mean Rank & Sum of Ranks & $\mathbf{Z}$ & Sig. \\
\hline \multirow{3}{*}{ Desire } & lower & 10 & 10.60 & 106.00 & \multirow{3}{*}{-0.076} & \multirow{3}{*}{0.939} \\
\hline & upper & 10 & 10.40 & 104.00 & & \\
\hline & Total & 20 & & & & \\
\hline \multirow{3}{*}{ Assertiveness } & lower & 10 & 11.45 & 114.50 & \multirow{3}{*}{-0.723} & \multirow{3}{*}{0.469} \\
\hline & upper & 10 & 9.55 & 95.50 & & \\
\hline & Total & 20 & & & & \\
\hline \multirow{3}{*}{ Sensitivity } & lower & 10 & 12.85 & 128.50 & \multirow{3}{*}{-1.801} & \multirow{3}{*}{0.072} \\
\hline & upper & 10 & 8.15 & 81.50 & & \\
\hline & Total & 20 & & & & \\
\hline \multirow{3}{*}{ Tension Control } & lower & 10 & 14.35 & 143.50 & \multirow{3}{*}{$-2.947^{*}$} & \multirow{3}{*}{0.003} \\
\hline & upper & 10 & 6.65 & 66.50 & & \\
\hline & Total & 20 & & & & \\
\hline \multirow{3}{*}{ Confidence } & lower & 10 & 14.60 & 146.00 & \multirow{3}{*}{$-3.130 *$} & \multirow{3}{*}{0.002} \\
\hline & upper & 10 & 6.40 & 64.00 & & \\
\hline & Total & 20 & & & & \\
\hline \multirow{3}{*}{$\begin{array}{c}\text { Personal } \\
\text { Accountability }\end{array}$} & lower & 10 & 12.65 & 126.50 & \multirow{3}{*}{-1.654} & \multirow{3}{*}{0.098} \\
\hline & upper & 10 & 8.35 & 83.50 & & \\
\hline & Total & 20 & & & & \\
\hline \multirow{3}{*}{ Self-Discipline } & lower & 10 & 13.65 & 136.50 & \multirow{3}{*}{$-2.404 *$} & \multirow{3}{*}{0.016} \\
\hline & upper & 10 & 7.35 & 73.50 & & \\
\hline & Total & 20 & & & & \\
\hline \multirow{3}{*}{$\begin{array}{l}\text { Information } \\
\text { Processing }\end{array}$} & lower & 10 & 15.10 & 151.00 & \multirow{3}{*}{$-3.488 *$} & \multirow{3}{*}{0.000} \\
\hline & upper & 10 & 5.90 & 59.00 & & \\
\hline & Total & 20 & & & & \\
\hline
\end{tabular}


$* P<0.05$ refers to $z$ values of \pm 1.96 .

Table 3 indicated that there are statistically significant differences between the upper and lower groups "Achievement level" in Tension Control, Confidence, Self-Discipline, and Information Processing. While there are no statistically significant differences between the two groups in each of Desire, Assertiveness, Sensitivity and Personal Accountability.

\section{Discussion}

The results of table (1) showed that the basic research sample obtained an intermediate level for all emotional response traits, as well as an intermediate level for processing information, as the arithmetic mean for the emotional response traits of the research sample ranged between 16.214 and 19.214, while it was 54.964 for information processing.

The results of table $(r)$ showed that there is statistically significant correlation between information processing and each of (Tension Control, Confidence, Self-Discipline). This explains that the emotional and cognitive systems exchange the effect, the different emotions make the brain work differently, including cognitive processes, and the cognitive performance of individuals who have positive emotions differs from individuals who have negative emotions, where positive emotions contribute to facilitate and stimulate cognitive processes such as thinking and decision making ability. (Taylor, J., 2010) confirms that negative emotions can hurt the Athlete mentally. his emotions are telling him that he's not confident in his ability to perform well and achieve his competitive goals. his confidence will decline, and he will have negative thoughts to go along with his negative emotions.

This is consistent with the study of (EImir, M., (2018) which concluded that there are correlations between cognitive processes and emotion, and that emotions greatly affect the processing of information as it has been concluded that the emotional system interferes with information processing, and then affects the processing, coding, storage and retrieval of information.

There is also a statistically significant correlation between achievement level, and each of (Sensitivity, Tension Control, Confidence, Self-Discipline, and Information Processing).

Fencing in particular is a very mental sport, as getting good as a fencer in practice is 95\% physical and 5\% mental. However, once you face off against your opponent, the percentages flip flop. Being successful is $95 \%$ mental and 5\% physical. And many theories and recent studies have emphasized the importance of emotions and their role in the cognitive aspect and in their impact on the capabilities of the individual to think and solve problems and organize and analyze information. Which clearly affects the level of achievement for the players. Where (Allawi, Radwan, 1987: 483) indicated that Confidence is the player's belief in his ability, confidence in his talent, and accepts challenges that test his capabilities, as well as expressing the player's knowledge of all aspects of his strength and weakness, and using them all to reach the best results, and it means that there is a willingness to face any obstacles within the limits of the player's capabilities.

(Ratib, O., 1997: 7, 8) also pointed out that Self-Discipline is a state of willingness to develop a "play plan", stick to it, integrate into it, reach it to the level of mastery over time, and the flexibility to change it. This feature represents the ability to maintain a "gameplay plan" as long as it is valid, and to abandon it after it has been proven invalid. Self-control or internal control of the player plays a prominent and important role in the development of the player's motivation towards sports performance

Fencers need to anticipate the opponent and to mask their true intentions with a game of feints and counterfeints, which must be supported by an adequate psycho-physical condition (Roi, G., Bianchedi D., 2008, 466.) This explains the importance of both information 
processing and the emotional state of fencing players as important factors affecting players 'achievement in competitions

Di Russo, F., Taddei, F., Apnile, T., \& Spinelli, D. (2006) points out that Flexible adaptation of behavior is highly required in some sports, such as fencing. In particular, stimulus discrimination and motor response selection and inhibition processes are crucial.

The results of table $(r)$ showed that there are statistically significant differences between the upper and lower groups "Achievement level" in Tension Control, Confidence, Self-Discipline, and Information Processing. While there are no statistically significant differences between the two groups in each of Desire, Assertiveness, Sensitivity and Personal Accountability.

Information processing is considered one of the most important dimensions of attention needed for fencing sports. In this regard, Hagemann et al. (2010) suggested that since fencing movements are extremely fast, early recognition of the target area of an opponent's attack is expected to be a key factor for success. This hypothesis was confirmed by the expert-advanced-novice differences observed under all of the experimental conditions. In particular, top-ranked fencers were able to extract markedly more information and use that information to predict the direction of their opponent's attack, it also helps to reject misleading movements, "such as deception or feints.

Emotions also play a very important role on the physical and mental performance of the players, as negative emotions can hurt performance both physically and mentally. as These emotions also sap the energy and cause Tired quickly. When the athlete experience despair and helplessness, the intensity drops sharply and he no longer has the physical capabilities to perform well (Taylor, J., 2010).

\section{Conclusions}

Based on results of this research, the following conclusions can be drawn:

1. There is a positive correlation between Information Processing and both (Tension Control, Confidence, Self-Discipline).

2. There is a positive correlation between Achievement level and (Sensitivity, Tension Control, Confidence, Self-Discipline, and Information Processing).

3. The availability of a good level of the emotional response traits (Tension Control, Confidence, Self-Discipline), and information processing is an important and effective factor in fencer's achievement level.

\section{Recommendations}

Based on the aim of the research and the collected data, the following implications can be made:

1. Focusing during players psychological preparation, on developing positive emotions, as it affects the players cognitive processes, such as Information Processing.

2. The necessity of measuring players emotions and cognitive aspects, as they affect the performance and achievement level. 


\section{References}

1. Abdel-Fattah, A. A., El-Ruby, A. O., (1986): Selecting the Gifted in the Sports Field, Alam El-Kotob, Cairo.

2. Abdel-Hamid, J., KazemA.K., (2002): Research Methods in Education and Psychology, Dar Al Nahda Al Arabiya for Publishing and Distribution, Cairo.

3. Allawi M. (1998): Psychological tests encyclopedia for athletes. Cairo: Book Publishing Center.

4. Annan, M. A., (1995): Psychology of Physical Education and Sports, (Theory, Practice and Experimentation), Dar Al-Fikr Al-Arabi, Cairo.

5. Azémar, G. (1999). La traumatologie spécifique révélée par la compétition en escrime. Schweizerische Zeitschrift fur Sportmedizin und Sporttraumatologie 47 (2), 79-80.

6. Bahy, M.H,. Al-Azhary, M.A., (2015): Scientific Research and Assessment Tools in the Educational, Psychological, Social, and Sports fields, The Anglo-Egyptian Library, Cairo.

7. Bahy, M.H., Salem, A.A., Mohamed M.S., (2015): The reference in applied statistics (theoretical - practical), The Anglo-Egyptian Library, Cairo.

8. Di Russo, F., Taddei, F., Apnile, T., \& Spinelli, D. (2006). Neural correlates of fast stimulus discrimination and response selection in top-level fencers, Neuroscience Letters, 408 (2), 113-118.

Doi:10.1016/j.neulet.2006.08.085

9. Elmir, M., (2018): The role of emotional processes in memory functioning, Arab journal of psychology, Issue 6.

10. Hagemann N, Schorer J, Cañal-Bruland R, Lotz S, Strauss B. (2010): Visual perception in fencing: Do the eye movements of fencers represent their information pickup? Atten Percept Psychophys, 72: 2204-2214.

11. Hasse, H., \& Mayer, H. (1978). Orientierun gsstrategien von Fechtern (Optical orientation strategies in fencers). Leistungssport, 8, 191-200.

12. Hijazi, M.K., Attention, (2013): Visual Perception and their Relationship to Sport Performance in Fencing, journal of human kinetics, V. (39), issue (1), pp 195-201.

DOI: https://doi.org/10.2478/hukin-2013-0082

13. LeDoux, J. (1996). The emotional brain: The mysterious underpinnings of emotional life. New York: Simon \& Schuster.

14. Marc V. Jones, (2003), Controlling emotions in sports, human kinetics publishers, The sports psychologists, $7,471-486$.

15. Melhem, S. M., (2002): Research Methods in Education and Psychology, Al Masirah House for Printing and Publishing, Amman, Jordan.

16. Ratib, O., (1997): Sports Psychology (Concepts, Implementation), Dar Al-Fikr AlArabi, Cairo.

17. Roi, G., Bianchedi D., (2008): The Science of Fencing, Sports Medicine 38(6), June, 465-481

\section{DOI: $10.2165 / 00007256-200838060-00003$}

18. Smith, Patricia L., Ragan, Tillman J. (2004): Instructional Design, John Wiley \& Sons. Inc., 3rd Ed., USA.

19. Taylor, J., (2010): Sports: The Power of Emotions. Do your emotions help or hurt you in the heat of competition?

Available at: https://www.psychologytoday.com/us/blog/the-power-prime/201012/sports-thepower-emotions 12/3/2018 
20. Tendler, A., Wagner, S., (2015): Different types of theta rhythmicity are induced by social and fearful stimuli in a network associated with social memory, eLife, 4:e03614.

DOI: $10.7554 /$ eLife.03614

21. Tyng CM, Amin HU, Saad MNM and Malik AS (2017): The Influences of Emotion on Learning and Memory. Front. Psychol. 8:1454. doi: 10.3389/fpsyg.2017.01454 